\title{
In the Classroom
}

\section{Teaching Soft Skills for Employability}

Joan Bartel

The Ministry for Immigration, Refugees and Citizenship Canada includes employment-related language training in its current initiatives. This article aims to contribute to the topic of teaching soft skills for job interviews and job retention, as informed by research from the fields of business and applied linguistics, including pragmatics, as well as insights from personal experience in employment-related classrooms. Ideas for lessons on some critical verbal and nonverbal soft skills are provided for employment-oriented classes at intermediate to advanced levels. Those skills focus on shaking hands, engaging in small talk, and asking questions

Immigration, Réfugiés et Citoyenneté Canada tient compte de l'apprentissage linguistique lié à l'emploi dans le cadre de ses initiatives actuelles. Cet article vise à contribuer au débat sur l'enseignement des compétences générales en lien avec les entrevues et l'embauche, et ce, à la lumière de recherches dans les domaines des affaires et de la linguistique appliquée, y compris la pragmatique et des intuitions tirées d'expériences personnelles vécues lors de cours liés à l'emploi. Des idées de cours sur certaines compétences générales verbales et non verbales essentielles sont présentées pour les cours centrés sur l'emploi aux niveaux intermédiaire et avancé. Ces cours portent sur l'art de serrer la main, de faire la conversation, et de poser les bonnes questions.

KEYWORDS: soft skills, employment-related language training, specialized language training (SLT), pragmatics, workplace English

\section{Introduction}

In the Ministry for Immigration, Refugees and Citizenship Canada's (IRCC) action plan "Helping Immigrants to Succeed," language training plays a significant role (Government of Canada, 2016). The IRCC is working towards a Pan-Canadian Language Strategy, in which one of three strategic themes is "Employment-related language training" (Teaching English as a second language [TESL] Ontario, 2016). Ontario's Ministry of Citizenship and Immigration names Specialized Language Training (SLT), "language training both for the workplace and in the workplace," as a current emphasis (TESL Ontario, 2016). Responding to those priorities, publicly funded intermediatelevel English as a second language (ESL) classes in the province now usu- 
ally include a unit on job search or workplace English; for example, about two-thirds of the Language Instruction for Newcomers (LINC - general ESL for settlement) classes include some instruction in English for the workplace (Citizenship and Immigration Canada [CIC], 2010, pp. vii, 44). A variety of SLT programs is available to immigrants in Ontario on a no-cost or low-cost basis, such as Workplace Communication (for example, delivered by school boards), Enhanced Language Training (ELT), Occupation-specific Language Training (OSLT), and Bridging programs. The curricula in such courses vary but most contain some acknowledgement of communication skills for the workplace beyond the grammar, vocabulary, and reading/writing/speaking/ listening skills typical in either General ESL or English for Academic Purposes.

Immigrants in Canada come from all over the world. Canadian employers cannot be expected to know the details of so many cultural differences without some guidance. In recent years, efforts have been made to educate employers about culturally different soft skills and benefits of diversity. Bhaskar lists 21 sources of information across Canada: one federal resource (www.hireimmigrants.ca) and 20 provincial or local initiatives (2015, p. 120). Nevertheless, the main onus is on immigrants to adapt to their new work environment.

Canadian TESL Certificate programs generally do not thoroughly cover employment-related communication, such as soft skills, in their theory and methodology (TESL Canada Federation, 2012, pp. 10-11; TESL Ontario, 2013, pp. 8-9). To help prepare ESL instructors to give meaningful lessons in this area, this article hopes to help fill the gap by reporting on some relevant research from the fields of business communication, applied linguistics, and language teaching and providing some sample lesson outlines.

The first half of this article discusses definitions and significance of soft skills, then looks at teaching materials for soft skills and pragmatics. The second half discusses four soft skills for employability that, according to studies, have a positive effect in job-related discourse. They focus on handshakes and the willingness to engage in small talk (nonverbal skills) and making small talk and asking questions (verbal skills). Some lesson ideas for teaching them are then outlined.

\section{A Definition of Soft Skills}

Since the late 1990s, use of the term "soft skills" has increased significantly (Collins, 2018) in business training, career advising, and job postings, where it is often equated with "interpersonal" or "people skills." They differ from technical or "hard skills." The latter, for example, those skills learned in classes on engineering, dentistry, accounting, or art, and so forth, can be more easily defined and assessed.

In the field of career advising, soft skills are seen as a considerable factor of employability and are often discussed in websites such as the Cana- 
dian sites CareerBuilder.ca and Workopolis.com, as well as many blogs of business consultants and others. However, definitions are often glossed over or exceedingly broad (see, for example, CareerBuilder, 2017), encompassing leadership skills, emotional intelligence, attitudes, and even personality traits. Moreover, because there is seldom any information available about the methodology of any study behind a proclaimed list of soft skills, such lists cannot be considered reliable.

Robles (2012) discusses the meaning of "soft skills" from the point of view of employers. She surveyed around 50 Kentucky business executives in two questionnaires. From the first, open-ended survey, almost 500 soft skills were collected. Those terms were coded and grouped in like themes, from which 26 emerged. The second questionnaire determined a list of the 10 most important ones. Based on her data, she concludes that, in employability discussions, a broad interpretation of soft skills is useful. The top 10 are, listed in order of importance, "integrity, communication, courtesy, responsibility, social skills, positive attitude, professionalism, flexibility, teamwork, and work ethic" (p. 453). Her list is a valuable reflection of the soft skills that employers consider "critical in today's workplace" (p. 463). She adds that it is difficult for educators to teach and assess these intangible attributes (p. 462). A discussion of whether personal qualities such as integrity and flexibility can actually be taught would go beyond the scope of this article; communication skills, however, can be addressed by language teachers.

In the literature of linguistics, the term "soft skills" rarely occurs, even among researchers cited in this article who are working with interview situations. In ESL textbooks for business and employment, it is often simply equated with "interpersonal skills." I have found it useful to define it similarly to the term "appropriacy" in linguistics, namely, a range of personal skills and behaviours: "self-awareness and cultural awareness as well as interpersonal skills, including verbal and nonverbal communication, that follow or reflect expected polite behaviour, especially in the business or workplace context" (Bartel , 2014, p. 110). Each of these skill types-self- and cultural awareness and communication - can be addressed within the context of a language class, and each plays a role in establishing appropriate personal relationships, in the classroom or community as well as at work.

\section{The Importance of Soft Skills for Career Success}

The possession of good soft skills is virtually a requirement for attaining, and retaining, most jobs in Canada. Communication skills are among the essential skills needed in a strong job candidate (Bhaskar, 2015; Lane \& Hirsch, 2012; Robles, 2012, cites further studies, p. 454).

How do immigrants fare in their job search in Canada? Are soft skills an issue? While a CIC report states that, for immigrants, language "is among the most serious barriers to finding employment" (CIC, 2010, p. 11), soft skills 
are not irrelevant (Lane \& Hirsch, 2012). A large poll shows that almost all employers and immigrant job-seekers understand the importance of both (Bhaskar, 2015, pp. 71-72).

For many newcomers, challenges in mastering the soft skills Canadian employers look for are linked to both language comprehension (i.e., understanding what other people are saying) and an understanding of the "Canadian" way of doing business. (Bhaskar, 2015, pp. 79-80)

If non-native speaker professionals emphasize only their technical qualifications and skills in the hiring process, they will have a hard time procuring a position. The lack of knowledge of the Canadian hiring process, that is, cultural awareness, is a clear disadvantage for them.

Newcomers need to understand the "unwritten rules" of Canadian work culture, expected workplace behaviour, in order to retain a job and succeed as well. Research from the field of social psychology shows that humans need to have some predictability in their lives in order to thrive. We "need to feel that we understand how the world works, that we can more or less anticipate what's going to happen, and that we can make things happen in our favor" (Grant Halvorson, 2015, pp. 173-174). For example, going into a business situation where introductions will be made, it would be helpful to be able to predict that a handshake will be expected and that someone might say, "How do you do?" Responses in that communication act could then be planned and rehearsed, for example, answering the question not with "Fine" but with "How do you do?" Introductions are especially fraught for people who do not shake hands with strangers of the opposite sex for religious reasons, as that behaviour is not anticipated by most Canadians. In order to "make things happen in our favor," having a practised response is a way to gain a sense of control.

It is in organized communication courses that newcomers' needs can best be met. There, they can become aware of, practise, and reflect upon behavioural expectations in the workplace, so that they can help to control their own futures.

\section{Selected ESL Teaching Materials Analysis}

As noted by Bartel (2014, p. 115), many employment-oriented ESL textbooks come up short on soft-skills lessons. A full review of the field is not possible within the confines of this article but two examples of teaching materials are briefly discussed here: a traditional workplace/business English textbook from a major publisher and an OSLT curriculum. (OSLT is funded by Immigration, Refugees and Citizenship Canada and delivered by Ontario colleges.)

An example of the former, Ventures: Transitions, which has as a goal "to help prepare adult students for success at work or in an academic setting" 
(Bitterlin, Johnson, Price, Ramirez, \& Savage, 2010, p. iii), laudably begins with a listening text about hard and soft skills. However, the topic is presented only for comprehension and grammar exercises within a structured all-skills unit, not for practice. Throughout the textbook, aside from an exercise on small talk, students are not required to actively produce any soft skills.

The curricula in Colleges Ontario's OSLT for various occupational fields mention soft skills only a few times in $300+$ pages, sometimes leaving it up to the instructor to define the term. In the curricula for both Technology and Health Sciences, for instance, the term is not described until near the end of the course, then simply as "interpersonal skills" (Technology, p. 416; Health Sciences, p. 321). Nonetheless, lists of examples of language used for complex interpersonal situations are provided throughout the second half of the curricula. For Technology, they are: requesting assistance from a coworker (pp. 292, 295), speaking directly versus indirectly (p. 317), exchanging opinions (p. 341), communicating assertively versus aggressively (pp. 348-349), diffusing a difficult situation (pp. 367-368, 373), and opening/closing networking conversations (p. 407). These lists exemplify language for soft skills, even though this is not explicitly explained.

ESL instructors who wish to teach full lessons on soft skills for employability may ultimately find it difficult to locate useful materials. Use of the term "soft skills" in a textbook does not guarantee that such skills are practised. However, some soft skills may be practised without being labelled as such. Careful analysis of materials is warranted.

\section{Similarities Between Teaching Soft Skills and Teaching Pragmatics}

For ESL instructors, one source of information about teaching soft skills, as well as some classroom materials, comes from the field of pragmatics. Pragmatic competence, concisely defined as the "ability to use language appropriately in social context" (Taguchi, 2016), is similar to competence in soft skills as defined narrowly above, that is, in "communication that follow[s] or reflect[s] expected polite behaviour." Thus, useful parallels for the language teaching context can be drawn between the two.

There is general agreement that pragmatics can be taught; see, for instance, Tatsuki and Houck (2010a, p. 2), who provide a list of research studies on the effectiveness of pragmatic instruction. However, as the Centre for Canadian Language Benchmarks (CCLB) states,

[Pragmatics] is one aspect of communicative competence that is particularly difficult for learners to acquire; cultural knowledge does not develop through exposure alone and therefore needs to be taught.

Learners need to develop an awareness of interpersonal norms in their new culture ... (CCLB, 2012, p. 71) 
Perhaps because of the difficulties involved, many ESL textbooks have not made pragmatics lessons a priority (Diepenbroek \& Derwing, 2014).

Among the pragmatics publications that are good sources of ideas and teaching strategies are works produced by the team of D. H. Tatsuki and N. R. Houck and the NorQuest College Centre for Intercultural Education. Tatsuki and Houck (2010b) and Houck and Tatsuki (2011) have edited valuable books that offer classroom-ready materials regarding specific speech acts, that is, verbal behaviour. While few are employment-related-but see Yates and Springall (2010) for a healthcare workplace scenario-some can be adapted, such as a lesson on asking for references (Akikawa \& Ishihara, 2010). NorQuest College Centre for Intercultural Education (2014) provides online workplace-situated lessons for five speech acts, using authentic language audios. These all suggest verbal material for the appropriate expression of soft skills. Norquest also produced a series of job interview videos with Guides that briefly refer to soft skills - more on those below, in lesson plans 2 and 3. (For pragmatics research in ESL contexts, see also the TESL Canada Journal Special Issue 2013, Yates [Ed.], 2014, a rich resource.)

In teaching a pragmatics lesson, one of the first steps is commonly awareness-raising of the speech act or issue to be studied. "Awareness-raising encourages noticing of and attention to forms and functions" (Olsher, 2017). This may be done in contextualized (workplace or classroom) situations. In a model pragmatics lesson, as taught in a Post-TESL Certificate Training (PTCT) course in Ontario (Bartel, 2014, pp. 122-123), the second step is to isolate the speech act or nonverbal behaviour. It is typically then explicitly explained (instruction stage) and augmented with further examples, where register and tone may be addressed. Students' understanding is checked before controlled and free $(\mathrm{r})$ practice stages are attempted.

When instructors in that PTCT tried teaching a pragmatics lesson, they found that their lessons were well received. They created in the classroom "an atmosphere of curiosity and interest, during which time the learners were engaged" and interacted genuinely (Bartel, 2014, p. 117).

\section{Four Soft Skills for Employability and Ideas for Lessons}

In the case of soft skills specifically for job interviews and job retention, that is, employability, the author's readings and experience teaching ELT and OSLT have shown that those that can be not only explained but also practised are a good starting point. Below are some lesson ideas. This article elaborates on only the following two nonverbal soft skills needed to meet interview and workplace expectations:

1. handshakes,

2. willingness to engage in small talk, 
and the following two verbal soft skills:

3. making small talk (to build rapport),

4. asking questions.

There are, of course, many other speech acts and nonverbal behaviours representing soft skills for employability, such as turn-taking in meetings and on the phone, interrupting, apologizing, opening/closing e-mails, requesting, and so on. (A lesson on requests in an Australian health workplace can be found in Yates and Springall [2010], for example.) The four skills above were chosen because there is evidence that proficiency in them adds greatly to the odds of success in interactions on the job or in an interview. Relevant research results are discussed before each lesson plan.

\section{Handshakes}

Handshakes are a normal part of job interviews, corporate or client meetings, and business introductions. In North America, they are generally genderneutral, according to this author's personal experience as well as etiquette experts, and there is a protocol (even if not everyone knows it): The senior person extends his or her hand to the junior person (Mayne, 2018, para 4), for a firm, not limp, handshake (Katz-Wilner, 2013; Laroche \& Rutherford, 2007, pp. 33, 109; Mayne, 2018; Stewart, Dustin, Barrick, \& Darnold, 2008, p. 1143).

During a lesson on handshakes, inevitably, some students will ask whether it really makes a difference how they do it. In fact, empirical research involving jobs with moderate to high social demands showed first, that "people present a consistent handshake," and second, that "individuals who follow common prescriptions for shaking hands, such as having a firm grip and looking the other person in the eye, receive higher ratings of employment suitability from interviewers" - ratings that reflect more than personal bias (Stewart et al., 2008, p. 1143). For all interviewees, but especially for women, it was found that a strong (firm) handshake was a characteristic of a strong candidate for a job, while a weak handshake was a characteristic of a weak candidate. Stewart et al., thus, suggest that handshake training could benefit women especially (2008, p. 1145).

Learning about handshakes can be successful and fun. Key steps in a lesson could be:

Awareness-raising/Isolation: Ask students about handshaking customs in their country of origin. Or follow the awareness-raising questions in Office Soft Skills, Unit 1 (Bartel, 2018).

Instruction: Students watch as the instructor demonstrates and explains a typical handshake in North America. Option: Read the Answer Key for Unit 1 in Office Soft Skills, where alternative behaviours and cultural differences 
are also discussed. First Nations people, for example, prefer a soft handshake (Laroche \& Rutherford, 2007, p. 109).

Contextualization/Examples: Watch a short video of different kinds of handshakes. For example, see Katz-Wilner (2013) - my students have enjoyed the visuals.

Controlled, guided practice: For practice and self-awareness, students practise handshakes with each other, giving feedback. They may enjoy using their cell phones to take pictures of each other shaking hands to observe posture, eye-contact, and so forth.

Assessment: Students shake hands with the instructor-or with a third person trained in evaluating handshakes whom the students do not know, such as an administrative or teaching colleague, an employer or a program consultant, in order to better simulate a real interview. They then receive feedback.

\section{Willingness to Engage in Small Talk (Nonverbal Behaviour)}

Job interviews are social interactions in which there is a power difference between the two interlocutors: the more powerful interviewer, representing the institution (company), and the less powerful candidate, who less often has (or takes) a chance to steer the conversation (Roberts \& Campbell, 2005). Two separate studies of interviews for low- to mid-level positions, such as warehouse or receptionist work, give insights into discourse patterns in interviews (Campbell \& Roberts, 2007 and Roberts \& Campbell, 2005; Kerekes 2004-all discussed below). It emerged that the willingness of a candidate to engage in small talk was a factor in his or her success in landing a job, irrespective of whether the candidate was a native speaker of English or not.

Kerekes (2004) reports on the importance of social interactions in a job interview. She analyzed 48 interview transcriptions, which included men and women candidates, both native speakers and non-native speakers of English in California. She found that an unwillingness to respond to an interviewer's question with more than a one-word answer was seen by the interviewer as an "undesirable characteristic of job candidates" (Kerekes, 2004, p. 30).

In the United Kingdom, Campbell and Roberts (2007), reporting on videotaped job interviews for similar jobs as above, noted that the discourse of job interviews required significant fluency and coherency. In addition, they found that "misalignments" in the conversation occurred, that is, "problems of understanding that were not caused by direct incomprehension, but rather by differences between participants' use of discourse" (p. 267), such as when a candidate hesitated to respond in more than a few words. In those cases, which took place more often with non-native speakers than native speakers, interviewers (the more powerful actors in the exchange) were likely to lose interest in the candidate, as shown by reduced eye contact and a lack 
of interest in posing more than the minimum required questions (Roberts \& Campbell, 2005, p. 65).

Can a willingness to speak up be taught? Students can at least be made aware of the significance of the speech act of responding to conversational overtures. This is especially important for phone conversations, a big part of daily work life, and, thus, employability, in many occupations. Hesitations can easily be misinterpreted when there is no eye contact. A willingness to engage can be shown through active listening with vocalizations and, in person, also with nonverbal behaviour such as nodding to show agreement and/ or understanding, as well as eye contact.

Useful lesson plans will vary depending on the context, for example, interviews or phone conversations (on-the-job employability). Again, awareness-raising is a good first step. A possible lesson plan could include any of the following:

Awareness-raising/Isolation: Model giving responses of one or few words with a straight face to students' questions or comments over a period of several minutes. Or invite a guest to class who fills that role.

Reflection, Instruction: Give students time to reflect on how they felt about receiving one-word responses. A discussion of their feelings, in small groups or as a class, can increase their self-awareness. Point out that such short replies can generate a feeling of discomfort in North American culture.

Contextualization/Examples: Show and discuss examples of successful or expected responses, that is, phone conversations or answers to common interview questions. For the latter, see, for example, NorQuest College Centre for Intercultural Education videos of scenarios with candidates of various background cultures; play the interview with Mei Li (https://www. youtube.com/watch? $v=I \_8-4 S t l v U \&$ feature=youtu.be) versus that of Louise (https://www.youtube.com/watch?v=epsoh1vZMio\&feature=youtu.be), and for a thoughtful, though too brief, analysis, add the Debriefing video as well (https://www.youtube.com/watch?v=U-5yywxrtOU).

Controlled and guided practice of student role-plays should follow. In student-centred classes, instructors could ask students for input on the type of conversation they think they need to practise, for instance, telephone calls or interview questions. If the latter, the Norquest videos could serve as a model; students could play the role of interviewee.

Specifically for job interviews, a knowledgeable instructor can explain responses to typical questions that are appropriate in North America. Discussions of cultural differences will ensue, as students compare Canadian customs with those in their country of origin. In my experience, those differences will likely include how much personal information to divulge and how to distinguish between boasting and stating one's strengths.

It is essential to note, however, that interview training can have a negative consequence; it is possible to rehearse interview answers too much. One of Campbell and Roberts' conclusions is that a memorized response is deemed 
untrustworthy. "[A]ny hint that the candidate is borrowing the words of others ... can be potentially used against them as a mark of inconsistency, untrustworthiness and non-belonging" (2007, p. 266). My own experience in teaching interview skills concurs with their observation: A memorized answer, particularly if it is phrased in vocabulary that the non-native speaker cannot use consistently throughout the dialogue, does not sound genuine. It goes against the most important attribute in Robles' list, integrity.

\section{Making Small Talk (to Build Rapport)}

Having established the importance of responses that are longer than a word or two, ESL instructors can help students with appropriate topics for small talk. Although disliked by many of my students whose culture does not encourage it, small talk is deemed a positive social skill in Canada and can help to build rapport between speakers.

A job interviewer is not simply confirming hard skills but also trying to picture the candidate in the workplace. Kerekes $(2004,2006)$ reports that, independent of the candidate's first language, interviewees who were able to uncover some common interests or experiences with their interlocutor had an advantage over those who could not. Successful candidates were able to show that they were members of a group that included the interviewer; for example, both were working mothers. As well, "the candidates who had the least (in terms of social factors) in common with their interviewers had the highest failure rate" (Kerekes, 2004, p. 28). In fact, it was found that once common ground, and thus co-membership, had been established in some way, interviewers dealt with weak answers in other areas of the interview more leniently (Kerekes, 2006, p. 54). I believe that this is true for coworkers as well; they will be friendlier with new hires who voluntarily seek rapport, for instance, by engaging in chit-chat with their peers, than with silent colleagues (Bartel, 2018, pp. 70, 78-79).

As for lessons for the ESL class, an effective awareness-raising activity is the juxtaposition of short answers versus engaged, chatty answers at the start of an interview, as seen in the NorQuest College Centre for Intercultural Education videos mentioned above, of Mei Li versus Louise. Students can be asked to identify any co-memberships that the candidates establish with an interviewer. Teachers should not be surprised, however, if, despite Louise's success, students from some cultures believe that Mei Li's performance is more appropriate. Again, the Debriefing section of NorQuest's videos allows for a thoughtful consideration of possible employer views of each behaviour.

There are various ways to follow up. Many textbooks and online sources introduce the subject of small talk with a guessing game or discussion of topics that are common versus taboo. Instructors can facilitate at first by modelling small talk, for example, by starting Mondays with the question "Did you have a good weekend?", and then by encouraging students to initiate (and 
conclude) such exchanges in class. Practice should be ongoing, so that students become comfortable with Canadian topics. To build students' knowledge base, teachers can lead the class in discussions of Canadian society (which is already a significant focus of LINC classes), such as the basics of political parties and the colours associated with them, so that students are not embarrassed if these are referenced during conversations in the real world. Photographs of government leaders as well as celebrities and sports teams, and so on, can be shown, in an effort to form common cultural ground for small talk even in the classroom. As Kerekes sums up,

Strategies of engaging in casual chit-chat in order to find common ground and establish co-membership can be addressed in ESL classes by teaching students to personalise their interactions, and to identify and volunteer information about themselves which they perceive will overlap with the interests or experiences of their interlocutor. (Kerekes, 2004, p. 37)

\section{Asking Questions}

Intermediate and advanced ESL students often feel they have "already learned questions" in previous English classes. Therefore, instruction in asking questions in the context of employment should highlight their appropriacy and soft skills such as respectfulness, rather than (or in addition to) grammar and syntax. Research done in Canada has shown that coworkers are often annoyed with open questions that they expect will take quite some time to answer, such as "I can't make heads or tails of the new guidelines! Can you help me ...?" because, in a busy office, "time pressure affects knowledge sharing" (Connelly, Ford, Turel, Gallupe, \& Zweig, 2014, p. 80). Thus, if new hires expect others to help them and to "make things happen in [their] favor" (Grant Halvorson, 2015, p. 173), they need to know Canadian soft skills for questions.

While Connelly et al. investigated knowledge-sharing among peers, Laroche and Rutherford write about the kinds of questions employees may ask their boss (2007, pp. 183-185). In Canada, it is not appropriate to show deference to a manager by continually asking open-endedly for his or her guidance or advice. Instead, North American bosses expect a certain amount of initiative from their staff, so employees should ask specific questions that show that they have already begun to work on the task.

Awareness-raising can be the first step of the lesson in ESL classrooms. Connelly et al., in their section "Implications for Practice," state that "individuals who are seeking assistance from colleagues may improve their likelihood of receiving knowledge by emphasizing how quickly it can be transmitted" (2014, p. 80). I have, therefore, found it useful to begin a lesson by comparing open versus focused questions, as the latter can be answered more quickly.

Awareness-raising/Isolation: Put two work-related questions on the board and ask students to discuss how much time it might take to answer 
each one. Connelly et al.'s examples include (a) "What is the acceptable mileage rate for car travel?" versus (b) "What do you know about the new conference travel guidelines?" (p. 80). I often use (a) Can you tell me where the colour option is on the copier? versus (b) How does the photocopier work? In both cases, the first question is focused, and easier to respond to, while the second is open.

Instruction, through examples: Give additional examples of questions, relevant to your students' occupational goals. Discuss why it might be important for new hires to recognize the qualitative difference between open and focused questions (namely, speed or efficiency of response, which influences the likelihood of receiving one). Encourage students to reflect on their own typical behaviour, that is, the kinds of questions they have asked you in class (self-awareness).

Verification of understanding: Verification occurs as students classify the sample questions as "open" or "focused."

Practice: Students practise by composing their own questions, relevant to classroom interchanges or a job interview, where candidates are expected to ask questions at the end. Where students have previous work experience, they should be able to create a role-play in their own occupational settings. I have found that they can imagine themselves as a new employee who needs to ask a coworker or boss questions about procedures in the new workplace.

\section{Conclusion: More Soft Skills Teaching Is Needed}

Both newcomers and employers understand that soft skills are an important part of workplace communication, but the main onus is on immigrant jobseekers and employees to become aware of them. Without knowing what Canadian employers are accustomed to, immigrant candidates are not able to successfully predict common soft skills and language expected in interviews and on the job. Thus, they cannot make meaningful choices as to how they want to look and act in order to achieve their goals. Therefore, it is appropriate for ESL instructors to introduce soft skills into lessons on workplace communication. However, ESL textbooks, even those published for employment-oriented classes, do not offer much designated practice with relevant speech acts and nonverbal behaviour.

This article has provided a review of research from the fields of business communication and applied linguistics to show that, in general, soft skills are critical factors for success in a job interview and at work (Bhaskar, 2015; Lane \& Hirsch, 2012; Robles, 2012). It has discussed the following specific soft skills, which, the given studies show, have a positive influence on employers' hiring and retention decisions: 
- Shaking hands: "Individuals who follow common prescriptions for shaking hands, such as having a firm grip ..., receive higher ratings of employment suitability from interviewers"' (Stewart et al., 2008, p. 1143).

- Willingness and ability to engage in small talk to build rapport: Candidates who answered interview questions in more than just a few words had more positive interactions with their interviewers than those who did not (Kerekes, 2004; Roberts \& Campbell, 2005, p. 65); and those who were able to find a common background or interest with their interviewer had a higher rate of job offers than those who could not (Kerekes, 2004 and 2006).

- Ability to ask efficient, focused questions: Because the business environment is time-sensitive, new employees who pose questions so that they can be answered quickly have a better chance of receiving a response, thus, successfully managing the situation and, by extension, retaining their job (Connelly et al., 2014).

We can teach our students to be aware of these skills. Some lesson ideas have been provided in this article. We can, as well, build their self-awareness of their preferred interaction styles. In the spirit of adult education, we should empower students to make their own choices. It is my hope that this article is a contribution to this field and that further studies and more resources for ESL for employability will be forthcoming.

\section{Acknowledgement}

I would like to thank the anonymous reviewers for their insightful comments on earlier versions of this article.

\section{The Author}

Joan Bartel writes and presents on communication and soft skills for interviewing and employment. She teaches Occupation-specific Language Training (OSLT) at Humber College and is the author of Office Soft Skills, a book for newcomers on effective communication for North American office workplaces. She also conducts interview workshops for Teaching English as a Second Language (TESL) students. Her background includes an MA in Language Teaching and certificates in Career Counselling.

\section{References}

Akikawa, K., \& Ishihara, N. (2010). Requesting a letter of recommendation: Teaching students to write e-mail requests. In D. H. Tatsuki \& N. R. Houck (Eds.), Pragmatics: Teaching speech acts (pp. 47-66). Alexandria, VA: TESOL.

Bartel, J. (2014). Pragmatics in the Post-TESL Certificate course "Language Teaching for Employment". TESL Canada Journal, 30 [Special Issue 7], 108-124. https://doi.org/10.18806/tesl. v30i7.1155 
Bartel, J. (2018). Office Soft Skills. 3rd edition. https://wayzgoosepress.com.

Bhaskar, R. (Ed.). (2015). Perceptions of employment barriers and solutions. Ottawa, ON: Canadian Electronic Library. Retrieved from http://www.hireimmigrants.ca/wp-content/uploads/Malatest_report_with_appendices.pdf

Bitterlin, G., Johnson, D., Price, D., Ramirez, S., \& Savage, K. L. (2010). Ventures: Transitions. New York: Cambridge University Press.

Campbell, S., \& Roberts, C. (2007). Migration, ethnicity and competing discourses in the job interview: Synthesizing the institutional and personal. Discourse $\mathcal{E}$ Society, 18(3), 243-271. doi:10.1177/0957926507075474

CareerBuilder.ca. (2017, May 1). What are soft skills and why are they important? Retrieved from http://www.careerbuilder.ca/blog/2017/05/01/what-are-soft-skil/

Centre for Canadian Language Benchmarks (CCLB). (2012). Incorporating pragmatics in a CLBbased program. In CLB support kit. II. Helping learners communicate effectively (pp. 71-98). Ottawa, ON: Author. Retrieved from http://bookshelf.language.ca/

Citizenship and Immigration Canada. (2010). Evaluation of the Language Instruction for Newcomers to Canada (LINC) Program. Retrieved from https://www.canada.ca/en/immigration-refugeescitizenship/corporate/reports-statistics/evaluations/language-instruction-newcomers-canada-2010/findings.html

Colleges Ontario. [2017 Online editions]. Technology and Health Sciences editions. Occupationspecific Language Training. (Available to OSLT instructors.)

Collins English Dictionary. [Online version]. (2018). HarperCollins Publishing. Retrieved from: https://www.collinsdictionary.com/dictionary/english/soft-skills

Connelly, C. E., Ford, D. P., Turel, O., Gallupe, B., \& Zweig, D. (2014). “I'm busy (and competitive)!" Antecedents of knowledge sharing under pressure. Knowledge Management Research E Practice, 12, 74-85. https://doi.org/10.1057/kmrp.2012.61

Diepenbroek, L., \& Derwing, T. (2014). To what extent do popular ESL textbooks incorporate oral fluency and pragmatic development. TESL Canada Journal, 30 [Special Issue 7], 1-20. https:// doi.org/10.18806/tesl.v30i7.1149

Government of Canada. (2016). 2015 Annual Report to Parliament on Immigration. Retrieved from http://www.cic.gc.ca/english/resources/publications/annual-report-2015/index.asp?_ ga $=1.219008784 .822354695 .1453320014$

Grant Halvorson, H. (2015). No one understands you and what to do about it. Boston, MA: Harvard Business Review Press.

Houck, N. R., \& Tatsuki, D. H. (Eds.). (2011). Pragmatics: Teaching natural conversation. Alexandria, VA: TESOL.

Katz-Wilner, L. (2013). The handshake: A key to effective communication skills. [Article and video]. Successfully Speaking. Retrieved from http://successfully-speaking.com/handshakekey-effective-communication-skills/

Kerekes, J. A. (2004). Preparing ESL learners for self-presentation in institutional settings outside the classroom. Prospect: An Australian Journal of TESOL, 19(1), 22-46. Retrieved from http:// hdl.handle.net/1959.14/328665

Kerekes, J. A. (2006). Winning an interviewer's trust in a gatekeeping encounter. Language in Society, 35(1), 27-57. doi:10.10170S0047404506060027 
Lane, J., \& Hirsch, T. (2012, September 6). Mind the gap: No people skills, no job. The Globe and Mail. Retrieved from http://www.theglobeandmail.com/opinion/mind-the-gap-no-peopleskills-no-job/article550966/

Laroche, L., \& Rutherford, D. (2007). Recruiting, retaining, and promoting culturally different employees. Burlington, MA: Butterworth-Heinemann (Elsevier).

NorQuest College Centre for Intercultural Education. (2012-2014). Pragmatic patterns for business. https://www.norquest.ca/professional-development/norquest-centres/centrefor-intercultural-education/projects/completed-projects/pragmatic-patterns-for-businessprofessional-language-competencies.aspx

Olsher, D. (2017, March 17). Awareness and discovery learning in teaching pragmatics. Paper presented at the International TESOL Convention [handout]. Seattle, WA.

Roberts, C., \& Campbell, S. (2005). Fitting stories into boxes: Rhetorical and textual constraints on candidates' performances in British job interviews. Journal of Applied Linguistics, 2(1), 45-73. doi:10.1558/japl.2005.2.1.45

Robles, M. M. (2012). Executive perceptions of the top 10 soft skills needed in today's workplace. Business Communication Quarterly, 75(4), 453-465. doi:10.1177/1080569912460400

Stewart, G. L., Dustin, S. L., Barrick, M. R., \& Darnold, T. C. (2008). Exploring the handshake in employment interviews. Journal of Applied Psychology, 93(5), 1139-1146. doi:10.1037/00219010.93.5.1139

Taguchi, N. (2016). Bio [on professional website]. Retrieved from https://www.cmu.edu/dietrich/ modlang/people/faculty/naoko-taguchi.html

Tatsuki, D. H., \& Houck, N. R. (2010a). Pragmatics from research to practice: Teaching speech acts. In D. H. Tatsuki \& N. R. Houck (Eds.), Pragmatics: Teaching speech acts (pp. 1-6). Alexandria, VA: TESOL. Retrieved from http://www.tesol.org/docs/default-source/books/677_sam. pdf?sfvrsn=2

Tatsuki, D. H., \& Houck, N. R. (Eds.). (2010b). Pragmatics: Teaching speech acts. Alexandria, VA: TESOL.

TESL Canada Federation. (2012). TESL Canada Federation teacher training program standards. Retrieved from http://www.tesl.ca/media/1670/rttp_explanation_standards_and_form.pdf

TESL Ontario. (2013). Institutional accreditation application (for TESL training programs). Retrieved from http://www.teslontario.net/uploads/accreditation/Institutions/InstitutionalAccred. Guide.pdf

Yates, L. (Ed.). (2014). TESL Canada Journal Special Issue, 30(7). Retrieved from http://teslcanadajournal.ca/index.php/tesl/issue/view/139

Yates, L., \& Springall, J. (2010). Soften up! Successful requests in the workplace. In D. H. Tatsuki \& N. R. Houck (Eds.), Pragmatics: Teaching speech acts (pp. 67-88). Alexandria, VA: TESOL. 